\title{
Technology and school leadership
}

\begin{abstract}
As the demand for schools to become more effective and efficient learning communities increases, the need for principals to cultivate broad-based, skilful participation in the work of leadership is essential. It is important for educational leaders to recognise the significance of their role in technology implementation and utilisation. They should be proficient in the use of technology and then provide leadership in the use of technology for administrative, instructional, and learning functions. Relatively few studies have empirically examined the level of computer use by principals, their perceived computer competence and their leadership style. This paper will report on these issues from an initial analysis of baseline data gathered from 30 secondary school principals in Tehran, a large province in Iran. Findings indicate that school principals spent a few times a week working on their computers and they had moderate levels of information technology competency. This paper also suggests that transformational leadership can help school leaders increase successful use of technology in schools. Hence, policy makers must design professional development programmes, such as leadership studies, in order to teach the components of transformational leadership: idealised influence, inspirational motivation, intellectual stimulation and individual consideration to future administrators.
\end{abstract}

Keyword: school principal, information communication technology 